\title{
A COUPLED TWO-PHASE MODEL FOR NUMERICAL SIMULATION OF A REAL DEBRIS AVALANCHE
}

\author{
Saeid M. Tayyebi ${ }^{\ddagger * *}$, Manuel Pastor ${ }^{\ddagger}$, Miguel M. Stickle ${ }^{\ddagger}$, Ángel Yagüe ${ }^{\dagger}$, \\ Diego Manzanal ${ }^{\dagger}$, Miguel Molinos ${ }^{\ddagger}$ and Pedro Navas ${ }^{\dagger}$ \\ ${ }^{\ddagger}$ Department of Applied Mathematics, ETS Ingenieros de Caminos, Canales y Puertos \\ Universidad Politécnica de Madrid \\ Calle del Profesor Aranguren, 3, 28040 Madrid Spain \\ *Correspondence: saeid.moussavita@alumnos.upm.es \\ ${ }^{\dagger}$ Department of Continuum Mechanics and Theory of Structures, ETSI Caminos, Canales y \\ Puertos \\ Universidad Politécnica de Madrid \\ Calle del Profesor Aranguren, 3, 28040 Madrid Spain
}

Key words: SPH, Coupled Problems, Two-phases Problem, Johnsons Landing Debris Avalanche

\begin{abstract}
Debris flows are characterized as mixtures of solid particles and pore fluids, in which coupling between phases plays a paramount role in the dynamic behaviour. Due to the strong coupling between phases, pore pressures can be generated if the fluidized mass contains solid particles with low permeability. As such, a two-phase propagationconsolidation model should be applied to take into account the motion of each constituent and the time-space evolution of pore-water pressure. In this regard, the capability of a depth-integrated two-phase model, recently developed by the authors, to study the coupled behaviour of solid and fluid in a fluidized geomaterial is evaluated. The developed model is based on the mixture theory in which balance of mass and linear momentum are established for each phase. The computational framework is based on the mesh-free smoothed particle hydrodynamics (SPH), incorporating a 1D finite-difference mesh describing pore pressure's evolution along the vertical distribution of flowing mass. The model is applied to simulate the Johnsons Landing debris avalanche in order to reproduce its complex behaviours, including bifurcation occurred at the mid-channel. The developed two-phase depth-integrated SPH-FD model is also applied to assess the structural countermeasure of the bottom drainage screen, used to reduce the impact of debris flows. The analysis of the results indicates the adequacy of the method to model large deformation of the two-phase materials over an impermeable and permeable bottom boundary. This suggests that the proposed particle-based method is a promising approach for future studies of coupled geophysical problems.
\end{abstract}




\section{INTRODUCTION}

Debris flows and debris avalanches are a special type of flows where solid and fluid particles have important relative movements. Unlike the avalanches, which can be described very well by one-phase continuum models, the debris flows require an accurate description taking into account the properties of both phases (stresses, volume fractions, and velocities) together with a suitable description of the interaction between them. Debris flows are characterized by their coupling between the phases and their effect on the dynamics behavior of the flow. To simulate such phenomena, a two-phase model is usually applied to reproduce the motion of each constituent during the propagation stage.

Hazard and risk assessment of landslides, with potentially long run-out, have attracted numerous researchers' attention in the past decades. The only way to limit risk is to have a better understanding of this phenomenon and its mechanism to develop more reliable predietion techniques. These objectives can be achieved using advanced simulation tools suitable for foreseeing the landslide run-out, frontal velocity, and deposit thickness. Several models have been developed during the last years to describe the propagation of fast landslide with a significant quantity of interstitial fluid. This paper applies a generalized depth-averaged two-phase propagation-consolidation model, recently developed by Pastor et al. (2021)[1]. The model is capable of reproducing the complex behavior

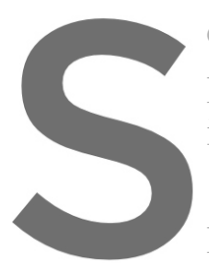
of fluidized mass wher
plays a determining ro
is essential.
The objectives are
presenting an alternat
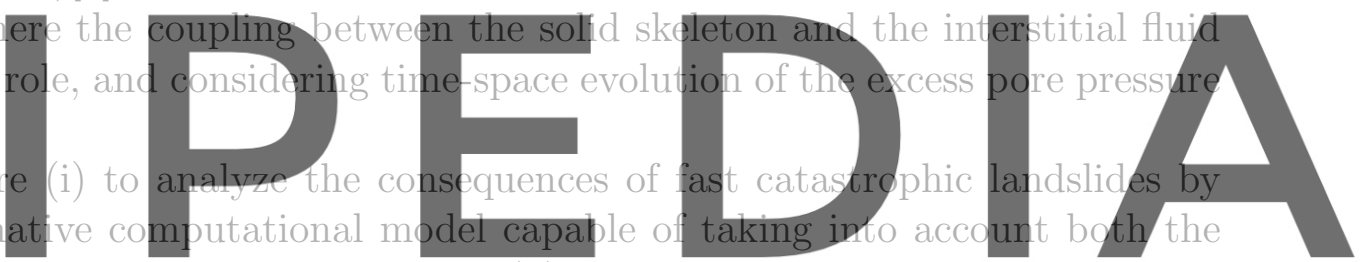

propagation and consolidation mechanisms and (ii) to study the efficiency of an energy-

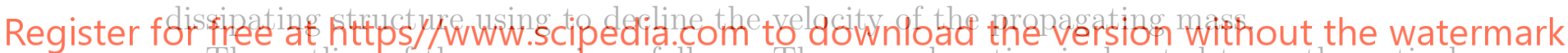

The outline of the paper is as follows. The second section is devoted to mathematical modeling, where the balance equations of mass and linear momentum for two-phase models are presented. These equations, together with a consolidation equation, a frictional rheological equation, and a drag law define the generalized two-phase model. Then, the mathematical models are then implemented in a numerical model where the propagation equations are discretized by using SPH, and the consolidation equation is discretized with two different methods of finite difference and quarter cosines shape function. In the third section, the main features of Johnsons Landing debris avalanche are described. Then, the numerical simulations of the debris avalanche are carried out through a two-phase model. Finally, conclusions arise from the comparison between the observed and numerical results. In the last section, the two-phase SPH-FD model is conducted to investigate the mechanisms of permeable screens on a small-scale flume test and the Johnsons Landing debris avalanche. 


\section{COMPUTATIONAL MODEL}

\subsection{Mathematical Model}

In landslide propagation, the fluidized geomaterials are mixtures of solid particles and pore fluids, in which coupling between them plays a paramount role in the behavior of geomaterials. Therefore, the mathematical model describing the problem has to implement this effect.

In this paper, the two-phase model proposed by Pastor et al. (2021)[1] is applied. The mathematical approach is based on the depth-integrated mathematical model of Zienkiewicz and Shiomi (1984)[2] and is similar to the two-phase models proposed by Pitman et al.(2005)[3] and Pudasaini (2012)[4]. The authors evaluated the capacity of the model to reproduce a debris flow on a laboratory scale inclined channel [5] and a real terrain [6] by comparing the numerical results with the measurements obtained from experiments and the data obtained from field in-depth investigation, respectively. The dynamics of the soil at propagation and consolidation stages are governed by balance equations of mass and linear momentum expressed in quasi-lagrangian form as follow:
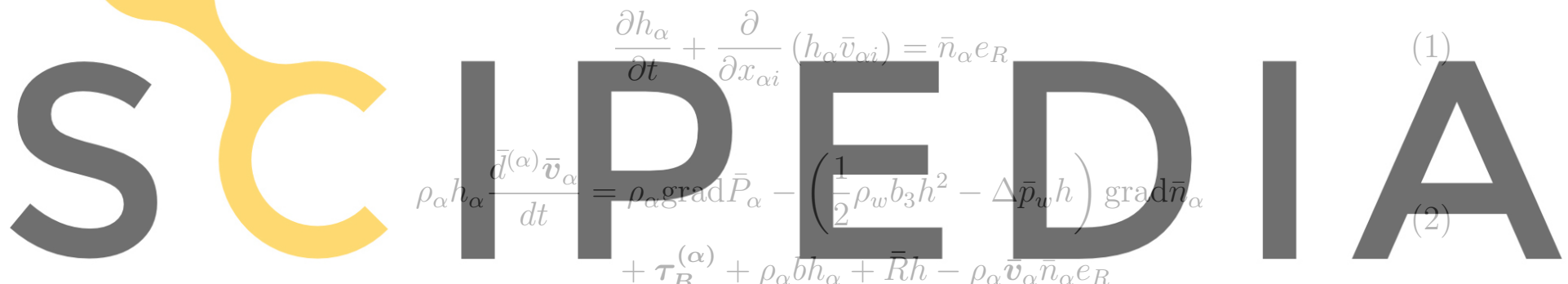

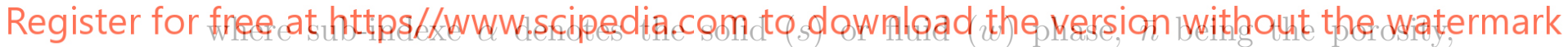

$e_{R}$ erosion rate, $b_{3}(=-\mathrm{g})$ is gravity force and its axis is vertical and points upwards. $\bar{P}_{s}=(1 / 2) b_{3} h h_{s}+\Delta \bar{p}_{w} h \bar{n} / \rho_{s}$ and $\bar{P}_{w}=(1 / 2) b_{3} h h_{w}-\bar{p}_{w} h \bar{n} / \rho_{w}$ are the averaged pressures acting on solid or fluid phases, respectively. $p_{h y d}$ is the hydrostatic pressure and $\Delta p_{w}$ an excess pore-water pressure.

One important aspect of fast landslides is pore pressure generation due to the strong coupling between phases. Coupling between the soil grains and the pore pressures was modeled by Pastor (2004)[7], who proposed a propagation-consolidation model to reproduce the run-out of debris flows. In this model, the evolution of pore pressure along the vertical axis is described as follows:

$$
\frac{d^{(s)} \Delta p_{w}}{d t}=-\rho_{d}^{\prime} b_{3} \frac{d h}{d t}+c_{v} \frac{\partial^{2} \Delta p_{w}}{\partial x_{3}^{2}}-E_{m} \frac{1}{(1-\bar{n})} \frac{d^{(s)} \bar{n}}{d t}
$$

where $\rho_{d}^{\prime}$ is the effective density, $c_{v}$ the consolidation coefficient and $E_{m}$ the oedometric modulus. 
In this two-phase model, each phase is described by its own balance equations, capable of considering the difference of velocities of both phases, where the interaction forces play an important role and couple the two sets of balance equations. In this study, the interaction force $(R)$ is provided by Anderson and Jackson law [8] which can be applied to cases with large relative velocity. It is given by:

$$
\bar{R}=\frac{\bar{n}(1-\bar{n})}{V_{T} \bar{n}^{m}}\left(\rho_{s}-\rho_{w}\right) \mathrm{g}\left(\overline{\boldsymbol{v}}_{w}-\overline{\boldsymbol{v}}_{s}\right)
$$

where $V_{T}$ is the terminal velocity, g the acceleration of gravity and $m$ a constant.

The basal shear stress $\left(\tau_{B}\right)$ is provided through voellmy's rheological law, a simple model where the cohesion and all viscous terms are disregarded. Besides, the model is capable of considering the effect of pore pressure at the basal surface. In the case of a pure frictional mass, the basal shear stress is given by:

$$
\tau_{B}=\left(\rho_{d}^{\prime} \mathrm{g} h-\Delta p_{w}^{b}\right) \frac{\overline{\boldsymbol{v}}_{i}}{|\overline{\boldsymbol{v}}|} \tan \phi_{B}+\rho \mathrm{g} \frac{|\overline{\boldsymbol{v}}|}{\xi} \overline{\boldsymbol{v}}_{i}
$$

where $h$ is the propagation height, $\phi_{B}$ the basal friction angle, $\bar{v}$ the depth averaged basal surface which Consider that the hig

2.2 Numerical Methods
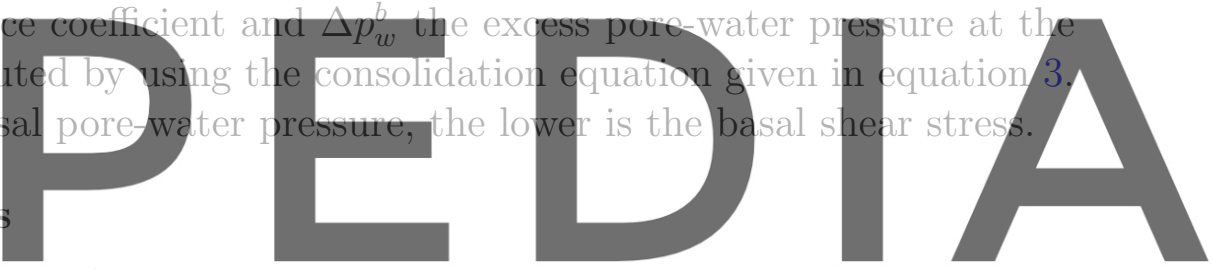

Next, the balance equations of mass and linear momentum, given in equations 1 and

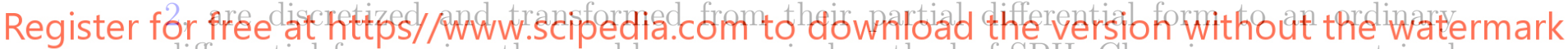
differential form using the meshless numerical method of SPH. Choosing a symmetrized form to discretize the gradient of the pressure and porosity, we obtain the following discretized forms of the balance equations of mass and linear momentum equation:

$$
\begin{aligned}
& \frac{\bar{d} h_{i}}{d t}+h_{i} \rho_{i} \sum_{j=1}^{N} m_{j}\left(\frac{\bar{v}_{j}}{\rho_{j}{ }^{2}}-\frac{\bar{v}_{i}}{\rho_{i}{ }^{2}}\right) \operatorname{grad} W_{i j}=\bar{n}_{i} e_{R} \\
\frac{\bar{d} \overline{\boldsymbol{v}}_{i}}{d t}=- & \sum_{j=1}^{N h} m_{j}\left(\frac{\bar{P}_{i}}{h_{i}^{2}}+\frac{\bar{P}_{j}}{h_{j}^{2}}\right) \operatorname{grad} W_{i j} \\
& -\left(\frac{1}{2} \frac{\rho_{w}}{\rho_{\alpha}} b_{3} h_{i}^{2}-\frac{\Delta \bar{p}_{w} h_{i}}{\rho_{\alpha}}\right) \sum_{j=1}^{N} m_{j}\left(\frac{\bar{n}_{i}}{h_{i}^{2}}+\frac{\bar{n}_{j}}{h_{j}^{2}}\right) \operatorname{grad} W_{i j} \\
& +\frac{1}{\rho_{\alpha} h_{i}} \boldsymbol{\tau}_{B}+b_{i}+\frac{1}{\rho_{\alpha}} \bar{R}-\frac{1}{h_{i}} \overline{\boldsymbol{v}}_{i} \bar{n}_{i} e_{R}
\end{aligned}
$$


Regarding the consolidation equation, two alternative methods are applied to describe the evolution of excess pore pressure. In the first alternative, the vertical distribution of pore-water pressure is approximated using a quarter cosines shape function, proposed by Pastor et al. (2004)[7], fulfilling boundary conditions with a zero value at the surface and zero gradient at the basal surface to approximate the vertical distribution of pore water pressure. It is given by:

$$
\frac{d^{(s)} \Delta p_{w}}{d t}=-\rho_{d}^{\prime} b_{3} \frac{d h}{d t}-\frac{c_{v} \pi^{2}}{4 h^{2}} \Delta p_{w}^{b}
$$

In the second alternative, the consolidation equation is discretized using the finite difference method. In a previous publication [9], the authors have addressed the problem of coupling SPH with a series of finite difference meshes associated to each SPH node, as shown in Fig. 1, which provides better accuracy to reproduce pore pressure changes. One of the advantages of incorporating a set of finite difference meshes and SPH nodes is its ability to simulate cases where basal pore pressures go to zero as a consequence of the landslide crossing a terrain with very high permeability.
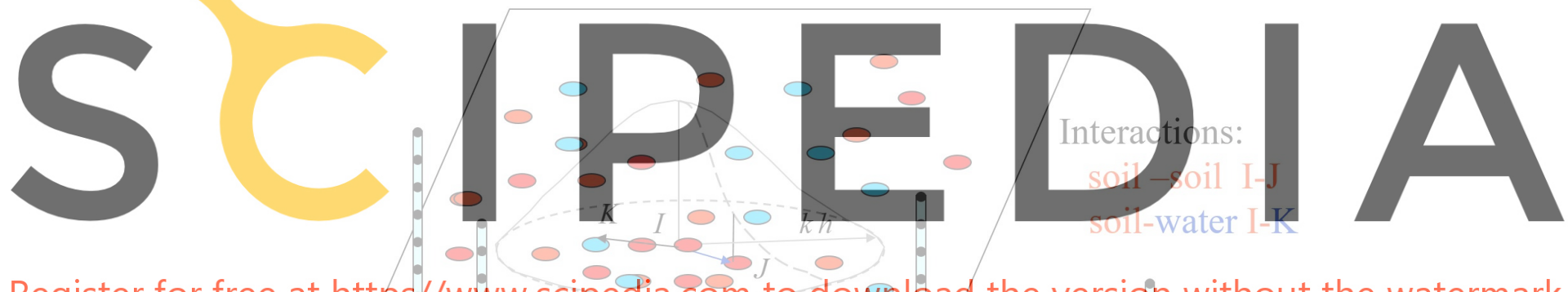

Register for free at https//www.scipedia.com to dowpload the version without the watermark

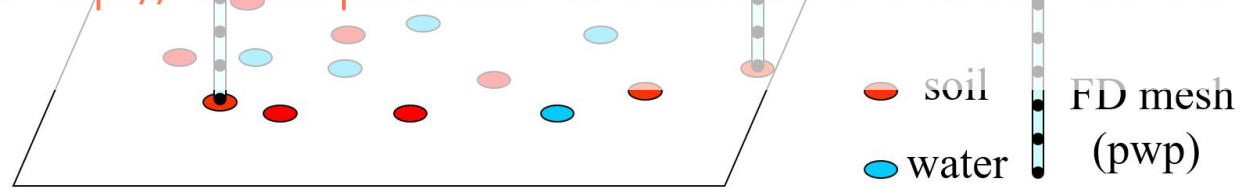

Figure 1: A 1D finite-difference mesh at each SPH node that represents solid particles.

We will rewrite the consolidation equation 5 in such a way that is more suitable for the formulation of FDM, as:

$$
\frac{d^{(s)} \Delta p_{w}}{d t}=-\rho_{d}^{\prime} b_{3} \frac{d h}{d t}\left(1-\frac{x_{3}}{h}\right)+c_{v} \frac{\partial^{2} \Delta p_{w}}{\partial x_{3}{ }^{2}}-E_{m} \frac{1}{(1-\bar{n})} \frac{d^{(s)} \bar{n}}{d t}
$$

where the consolidation equation is discretized by taking into account height and porosity variation. 


\section{CASE STUDY: JOHNSONS LANDING DEBRIS AVALANCHE}

The Johnsons Landing landslide is a real case exercise proposed by the Second JTC1 Workshop [10] to benchmark the capabilities of recent computational models. It was selected based on the information provided by Nicol et al. (2013)[11] who conducted an in-depth investigation on the day of the debris avalanche, including topography, initial thickness deposit trim-line, and the distribution of deposit volume.

It occurred approximately two kilometers northeast of the small community of Johnsons Landing, located on Kootenay Lake, on July 12th, 2012. Figure 2 provides a general view of the avalanche and its location.
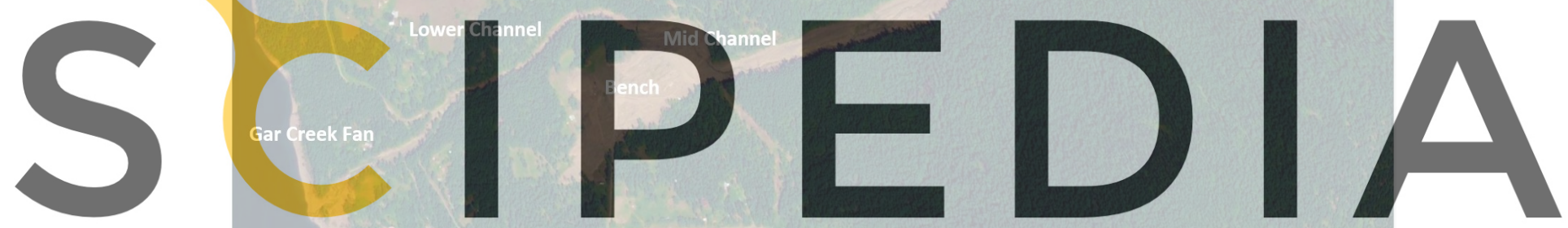

Register for free at https//www.scipedia.com to download the version without the watermark

Figure 2: Aerial view of the Johnsons Landing debris avalanche.

As shown in Figure 2, the debris avalanche was triggered in the upper channel where the unstable materials, include soil and rock, flowed into the Gar Creek channel. Then, a small portion of the material flow avulsed from the mid-channel at a sharp bend and travel along the drainage line until it reached the Gar Creek Fan. A video of this second event is available online. Much of the debris avalanche flowed out of the channel, ran down to the Johnsons Landing bench, and spread out over the terrace surface, causing the loss of four fatalities and the damage of several homes and a public road. From the modeling point of view, the key challenge is to reproduce the process of the debris avalanche flowing along the channel until it reached the mid-channel, where the debris avalanche flowed out and ran down to the Johnsons Landing bench. 


\subsection{Numerical results}

The numerical analysis of Johnsons Landing debris avalanche is performed through a depth-integrated two-phase model proposed by Pastor et al.(2021)[1]. The Johnsons Landing debris avalanche has been studied with the frictional rheological model, and the vertical distribution of excess pore-water pressure is approximated using a quarter cosines shape function (see equation 8). Flow parameters and coefficient required for the model are given in Table 1.

Table 1: Material parameters used in the analysis of the avalanche.

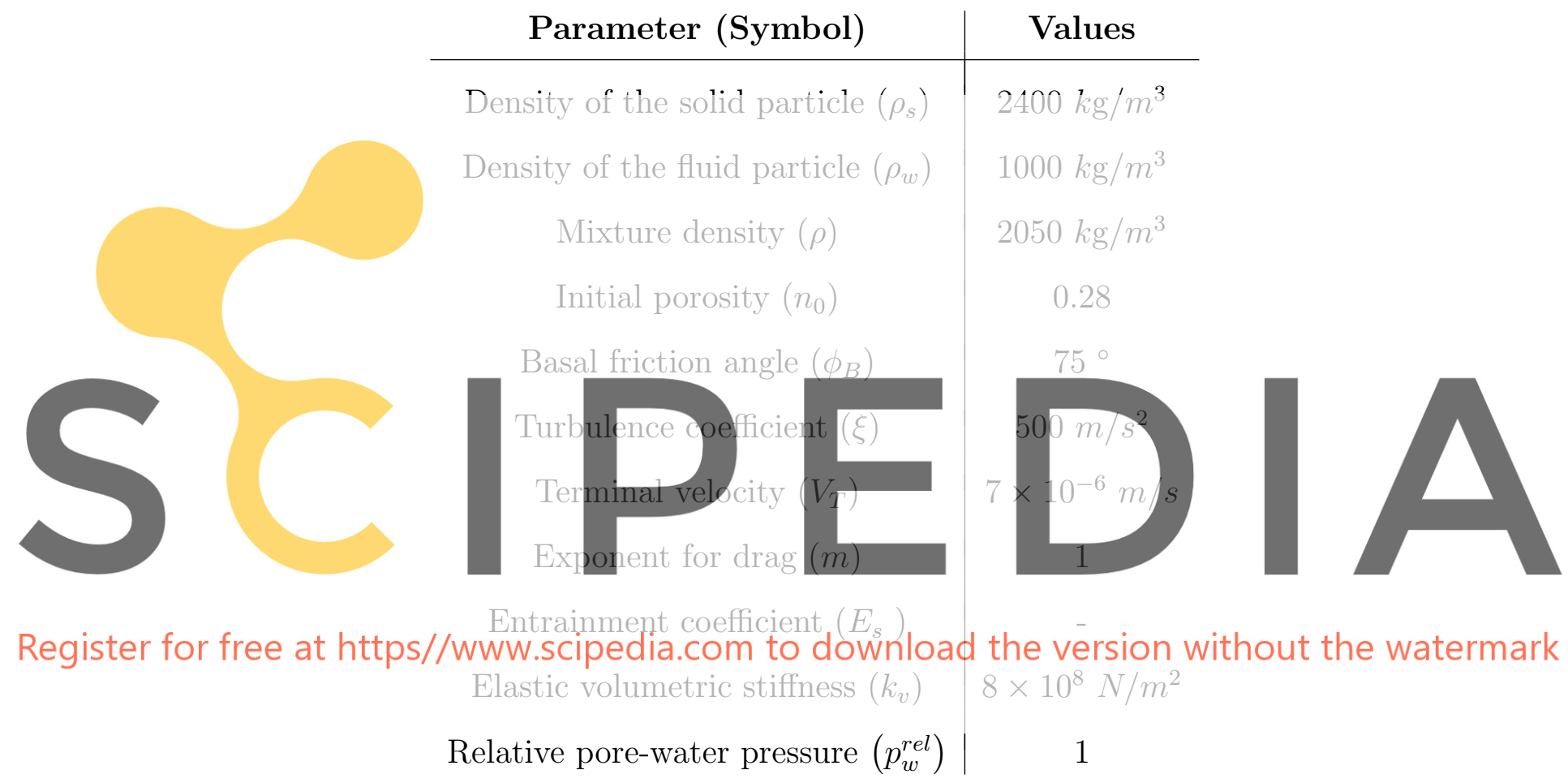

In Figure 3, we provide a topographical map showing the landslide path, final deposition, and the observed impact area produced by the presented model. By comparing the deposit shapes obtained from simulation and observed results, we can see that the deposit shape of the debris avalanche was reasonably predicted in all the zones. The deposited material could well spread in the upper channel, the mid-channel, and the bench.

\subsection{Bottom drainage screens}

In this section, a coupled SPH and finite-difference (SPH-FD) approach, described in section 2.2 , is applied to reproduce the dynamics behavior of a debris avalanche equipped by the structural countermeasure of bottom drainage screens which is an energy dissipation structure designed to reduce velocities and run-out distances of fast landslide. This 


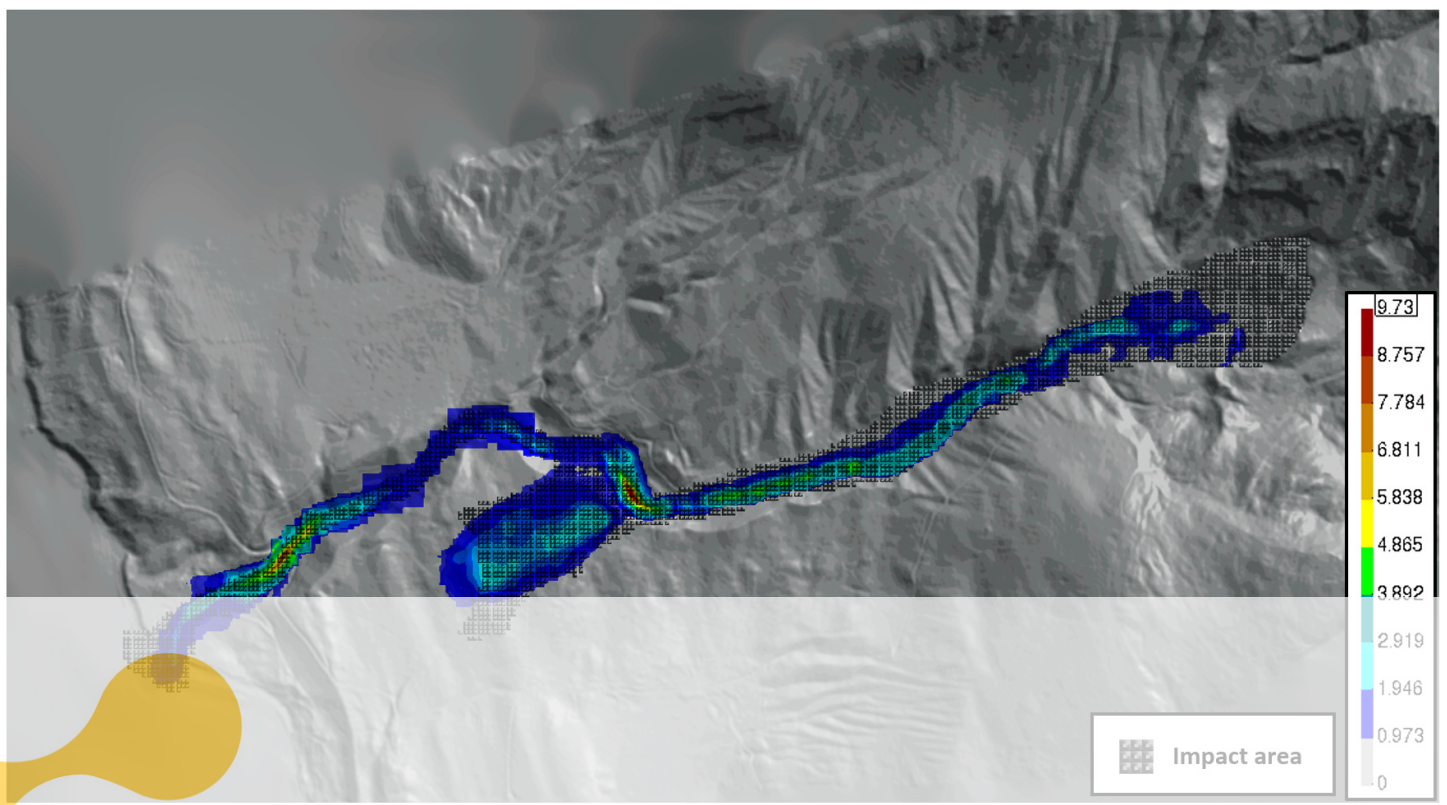

Figure 3: The numerical result of final deposit thickness using two-phase SPH model.
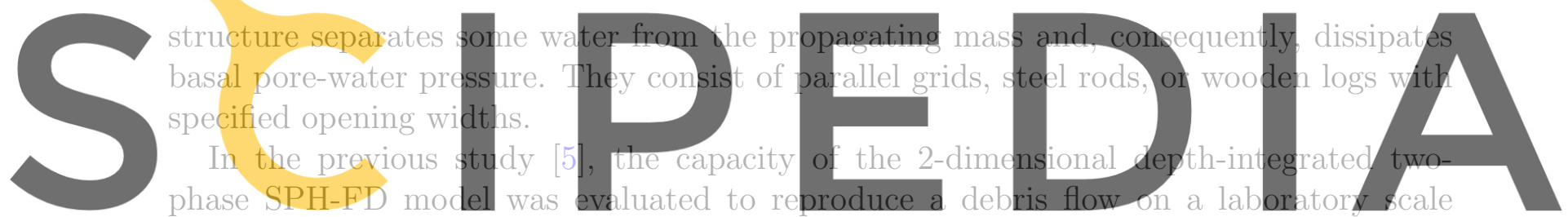

inclined channel by comparing the numerical results with the measurements obtained from

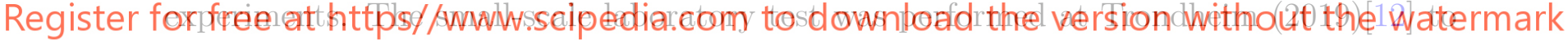

illustrate the performance of the permeable debris flow screen on the propagation of debris flows.

In this paper, the two-phase SPH-FD model is conducted to investigate the mechanisms of bottom drainage screens on a real debris avalanche. First, we start with 3-dimensional depth-integrated modeling of the mentioned flume test.

As shown in Figure 4, The flume test was performed in a $10 \mathrm{~m}$ long channel and had two parts: the main channel and a deposition area. The former is $6 \mathrm{~m}$ long and $0.3 \mathrm{~m}$ wide, with a $17^{\circ}$ inclination, and the latter is $4 m$ long and $2.2 m$ wide, with a $2^{\circ}$ inclination. In Figure 4-a, the initial configuration of the fully saturated debris material is depicted. The source material has a total volume of $25 \mathrm{~L}$ and a solid concentration of $60 \%$. Therefore, the densities of soil particles, interstitial fluid and, mixture have been taken with the values of $2750 \mathrm{~kg} / \mathrm{m}^{3}, 1000 \mathrm{~kg} / \mathrm{m}^{3}$, and $2050 \mathrm{~kg} / \mathrm{m}^{3}$, respectively. Figure 4-b shows that the flowing mass is propagating through the boundary wall at the main channel.

As depicted in Figure 4-c, once a debris flow crosses the permeable screen, it brakes, and the speed of the solid particles declines rapidly. At this stage, the excess pore-water 


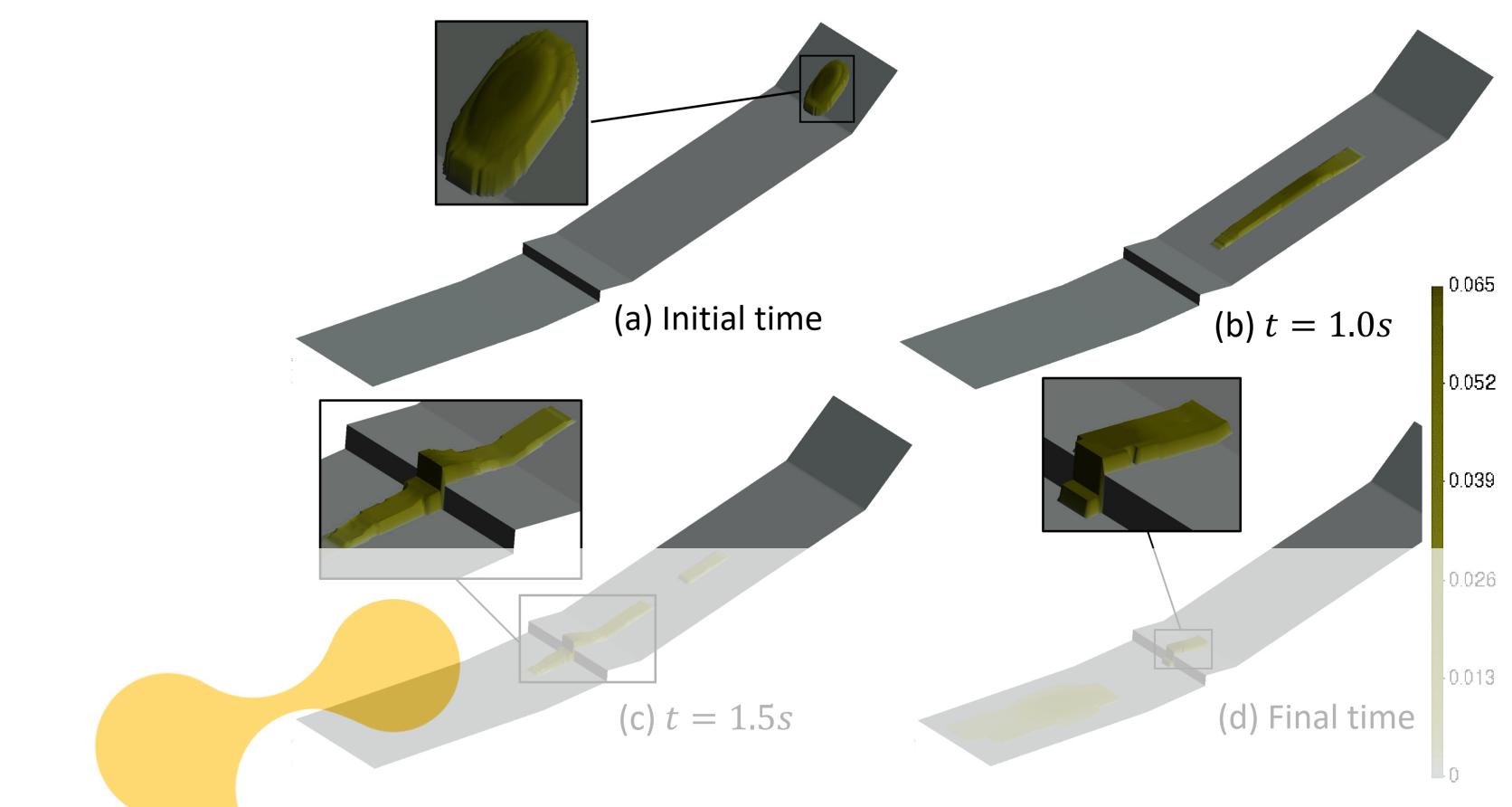

Figure 4: 3D depth-integrated modeling of a flume test equipped by a bottom drainage screen.

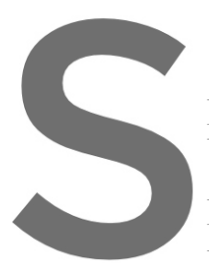
pressure instantly becomes qqual, but opposite in sign, to
basal surface. As a result, the basal total pore-water pr
pore-water pressure still exists in the body of the landslic
regain their contact friction. Therefore, the shearing re
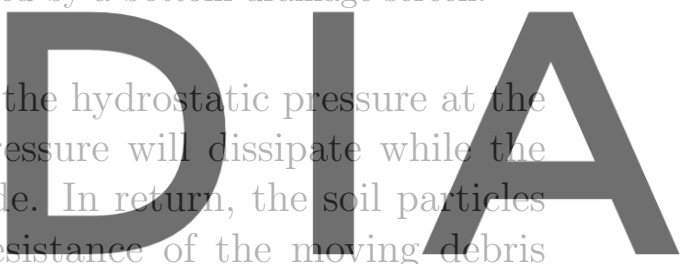

increases, which the presented model can consider it using frictional rheological law given

Register for freethth ht.tps//www.scipedia.com to download the version without the watermark

In Figure 4-d, two distinguishing parts of the debris deposit have been shown: (i) The

first is the debris mass accumülation which took place over the screen with an accumülation height of $6 \mathrm{~cm}$. (ii) The second is the debris mass accumulated with a maximum height of $2 \mathrm{~cm}$ in the deposition area. Results are satisfactorily reproducing the runout distance and final deposition height of the fume test over the screen and the deposition area.

Next, the two-phase SPH-FD model is conducted to investigate the mechanisms of bottom drainage screens on a real debris avalanche. As shown in Figure 5, the geometric data of the topography was modified to consider two bottom drainage screens along the propagation path. To have the highest efficiency, the first screen was located at the toe of the upper channel for the advantage of having a relatively gentler slope and a narrower width. It is designed to reduce the velocity and prevent overtopping of the flowing mass. The second screen was located at the crown of the lower channel to stop the mobilized volume of the debris avalanche from accelerating and travelling down.

Forward analyses have been conducted using the same rheological and consolidation 


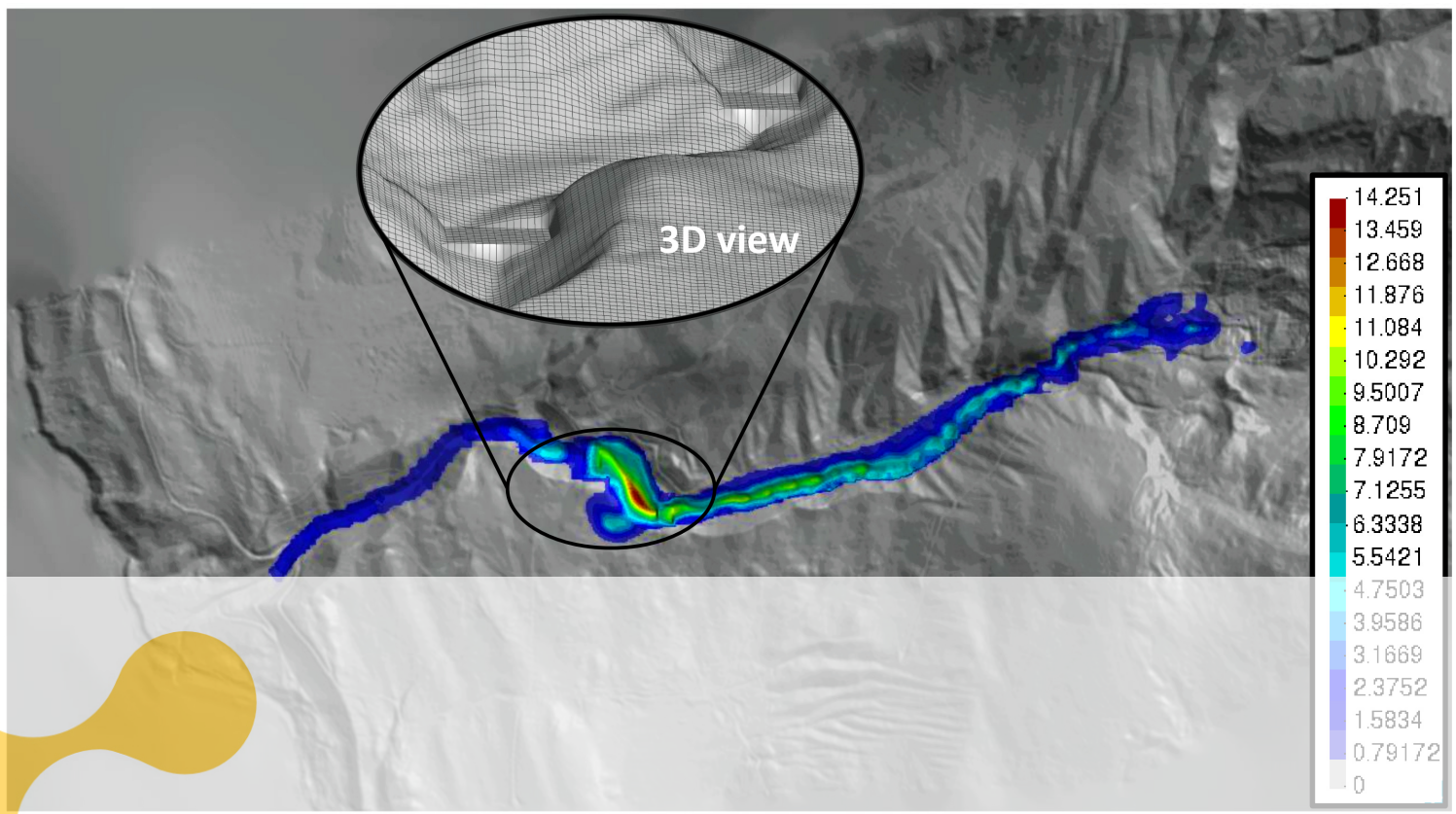

Figure 5: The final deposition thickness of the debris avalanche with two bottom drainage screens.
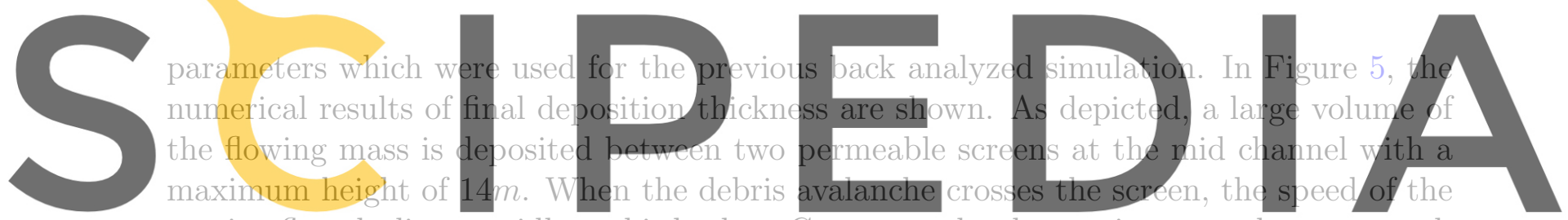

moving flow declines rapidly and it brakes. Consequently, the moving mass does not reach

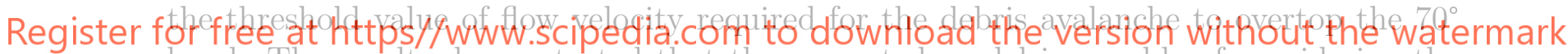
bend. The results demonstrated that the presented model is capable of considering the impact of terrain with high permeability and properly describe the behavior of a debris flow propagating over a bottom drainage screen.

\section{CONCLUSIONS}

- This paper aims to validate a generalized two-phase model to study the coupled behaviour of fluid and solid phases in a fast landslide. The key feature of the presented model is that the velocities of both solid and fluid phases and the interaction between them are considered.

- In the first simulation analysis, the real case of Johnsons landing debris avalanche was modeled through the two-phase SPH model. In the second simulation analysis, the two-phase SPH-FD model was applied to simulate a flume test equipped with a bottom drainage screen. In the last simulation analysis, the two-phase SPH-FD model was applied to forward analysis of the Johnsons landing debris avalanche with the assumption that there exist two bottom drainage screens along the propagation 
path.

- The reasonable results obtained from the analysis indicates that the model is capable to properly reproduce the propagation of the debris flow and, more importantly, to correctly perform the time-space evolution of pore water pressures during the whole deformation process from initiation through propagation, over an impermeable and permeable bottom boundary, up to deposition.

- The capability of the SPH technique to model a large deformation of soils and finite difference mesh to compute the distribution of pore pressure along the vertical axis make the presented two-phase model a promising approach for future studies of coupled problems.

\section{Acknowledgement}

The authors gratefully acknowledge the economic support provided by the Spanish Ministry MINECO under project P-LAND (PID2019-105630GB-I00). In addition, the authors gratefully acknowledge the support of the Geotechnical Engineering Office, Civil Engineering and Development Department of the Government of the Hong Kong SAR in the provision of the digital terrain models for the Canada landslide case..

\section{REFERENCES}

[1] M. Pastor, S.M. Tayyebi, M.M. Stickle, A. Yagüe, M. Molinos, P. Navas, and D. Manzanal. A depth integrated, coupled, two-phase model for debris flow propagation. Acta Geotech., pages 1-25, jan 2021.

[2] O. C. Zienkiewicz and T. Shiomi. Dynamic behaviour of saturated porous media; The generalized Biot formulation and its numerical solution. Int. J. Numer. Anal. Methods Geomech., 8(1):71-96, jan 1984.

[3] E. B. Pitman and L. Le. A two-fluid model for avalanche and debris flows. Philos. Trans. R. Soc. A Math. Phys. Eng. Sci., 363(1832):1573-1601, jul 2005.

[4] Shiva P. Pudasaini. A general two-phase debris flow model. J. Geophys. Res. Earth Surf., 117(F3):F03010, sep 2012.

[5] S. M. Tayyebi. A two-phase SPH depth integrated model for debris flow propagation considering pore water pressure evolution. $\mathrm{PhD}$ thesis, Universidad Politécnica de Madrid, 2019.

[6] S. M. Tayyebi, M. Pastor, and M. Stickle. Two-phase SPH numerical study of pore-water pressure effect on debris flows mobility: Yu Tung debris flow. Comput. Geotech., 132:103973, apr 2021. 
[7] M. Pastor, M. Quecedo, E. Gonzalez, M. I. Herreros, J. A. Merodo, and P. Mira. Modelling of Landslides: (II) Propagation. In Félix Darve and Ioannis Vardoulakis, editors, Degrad. Instab. Geomaterials, pages 319-367. Springer Vienna, Vienna, 2004.

[8] T. B. Anderson and R. Jackson. Fluid Mechanical Description of Fluidized Beds. Equations of Motion. Ind. Eng. Chem. Fundam., 6(4):527-539, nov 1967.

[9] M. Pastor, T. Blanc, B. Haddad, V. Drempetic, M. S. Morles, P. Dutto, M. M. Stickle, P. Mira, and J. A. Merodo. Depth Averaged Models for Fast Landslide Propagation: Mathematical, Rheological and Numerical Aspects. Arch. Comput. Methods Eng., 22(1):67-104, jan 2015.

[10] M. Pastor, S.M. Tayyebi, A. Yagüe, M.M. Stickle, D. Manzanal, M. Molinos, B. Haddad, D. Palacios, C. Lin, T.C. Li, and X.Q. Liu. A SPH depth integrated model with pore pressure coupling for fast landslides and related phenomena. In Second JTC1 Work. Triggering Propag. Rapid Flow-like Landslides, page 222, Hong Kong, 2018.

[11] D. Nicol, P. Jordan, D. Boyer, and D. Yonin. Regional District of Central Kootenay ( RDCK ) Johnsons Landing Landslide Hazard and Risk Assessment. Technical report, 2013.

[12] A. L. Yifru. Investigation of a screen structure for mitigating debris-flows along coastal roads. PhD thesis, NTNU, 2020. 